\title{
Simulate The Process of Preparing Biochar By Pyrolysis of Biomass Via Aspen Plus And Evaluate Its Economic
}

\section{Yanbing Liu}

Jiangsu University of Science and Technology

\section{Zongyuan Zhu}

Jiangsu University of Science and Technology

Jiaqi Zhang

Jiangsu University of Science and Technology

Xinglin Yang ( $\square$ yangxl233@163.com )

Jiangsu University of Science and Technology

\section{Research Article}

Keywords: Biochar, Aspen Plus, Pyrolysis, Life cycle cost, Economic

Posted Date: July 29th, 2021

DOI: https://doi.org/10.21203/rs.3.rs-680405/v1

License: (c) (i) This work is licensed under a Creative Commons Attribution 4.0 International License. Read Full License 


\section{Abstract}

China is a big agricultural country and generates a lot of biomass waste every year. Biomass is the only renewable carbon source. Biochar can be produced by pyrolysis under anaerobic or hypoxic conditions. Biochar has a rich pore structure, large specific surface area and special adsorption properties, and has been widely used in different industries. Different raw materials and pyrolysis temperature will have different effects on the yield and pore structure of Biochar. During our research, a flow chart was established in Aspen Plus V8.4 software to simulate the pyrolysis process of rice straw and sugarcane bagasse, and the feasibility of the model was verified through experiment. The results show that the simulated value of biochar yield is different from the experimental value. The difference is small at low temperature $\left(300-500^{\circ} \mathrm{C}\right)$, and larger at high temperature $\left(600-800^{\circ} \mathrm{C}\right)$, but both remain between $0.55 \%$ and $13.11 \%$. Finally, the Life Cycle Cost (LCC) method was used to evaluate the economics of the process of preparing biochar from $1 \mathrm{t}$ rice straw and sugarcane bagasse. The cost of rice straw and sugarcane bagasse biochar were 0.79 and $0.93 \mathrm{USD} / \mathrm{kg}$, respectively. Considering from the aspects of yield, pore structure, energy consumption, and economy of biochar, compared with sugarcane bagasse, rice straw has a more competitive advantage in the preparation of biochar.

\section{State Of Novelty}

Establish biomass (rice straw and sugarcane bagasse) pyrolysis model in Aspen Plus software, and verify the feasibility of the model through experimental results. Only by measuring the content of cellulose, hemicellulose and lignin in the biomass, the yield of biochar can be predicted by simulation. In addition, the economic analysis of the pyrolysis process using the LCC method shows that the economics of biochar are favorable.

\section{Introduction}

At present, a large amount of biomass waste is generated in agricultural industrial production, which has caused a serious burden on the environment [1]. According to statistics, the world's annual output of biomass is about 220 billion tons (dry matter), 70\% of which is about crop straw [2,3]. People mostly use traditional direct combustion to treat biomass, which not only causes unwarranted waste of agricultural resources, but also causes serious air pollution $[4,5]$. If we pyrolyze biomass at high temperature under oxygen-limited conditions, we can get carbon-rich solid particles, namely biochar [6, 7]. Biochar usually exhibits rich pore structure, large specific surface area, high stability, special adsorption properties and higher surface energy [8-11]. Because of these unique properties and structures, biochar has been widely used in catalyst carriers [12], soil additives [13], adsorbents [14], and lithium battery anode materials [15]. Moreover, biomass is the only renewable carbon source [16], so it is particularly important to study biomass to prepare biochar. Biomass prepares biochar required by multiple industries through pyrolysis, which solves the problem of disposal of a large number of biomass resources, turns waste into treasure, and realizes the recyclable utilization of resources. 
Compared with other utilization methods of biomass (gasification, liquefaction, fermentation, etc.), the high-temperature pyrolysis process of biomass has a higher conversion efficiency and requires a shorter reaction time [17]. In the process of biomass pyrolysis, temperature, heating rate, material characteristics and other parameters all have a certain impact on the yield of biochar $[18,19]$. Among them, the pyrolysis temperature has a greater impact on the biochar yield $[20,21]$. When the temperature is low, the biomass cannot be completely degraded to form carbon materials. When the temperature is high, the carbon materials will be secondary pyrolyzed, and the yield of biochar will decrease $[18,22,23]$. Therefore, it is necessary to explore the effect of pyrolysis temperature on the yield of biochar through a certain method.

In this study, rice straw and sugarcane bagasse were selected as the biomass raw materials. Firstly, the chemical simulation software Aspen Plus V8.4 was used to establish a biomass pyrolysis flow chart. According to different pyrolysis conditions and reactions, an appropriate model was selected to explore the influence of temperature changes on biochar production. At the same time, the heat duty of the reactor at different pyrolysis temperatures can be obtained in the software simulation, and the reaction process can be analyzed from the perspective of heat balance. Secondly, a tube furnace is used to pyrolyze the biomass in a nitrogen stream, and the biochar yield is calculated based on the mass ratio of the obtained biochar to the raw material. Setting different pyrolysis temperatures to explore the influence of temperature on biochar production. The results are compared with the software simulation results, and summarize general laws to provide a certain theoretical basis for the industrial pyrolysis of biomass. We should note that economy is the main factor restricting the development of product industries, and researchers at home and abroad have hardly evaluated the economics of biochar. It can be seen from the foregoing description that using waste resource biomass as raw material to prepare biochar with a wide range of uses and good performance through high-temperature pyrolysis is a better method to dispose of biomass resources. Therefore, this study uses the Life Cycle Cost (LCC) method to evaluate the economics of biochar in order to provide a reference for the future development of biomass and the market pricing of biochar.

\section{Simulation Study}

\subsection{Methodology}

The commercial software Aspen Plus V8.4 is a large-scale general-purpose process simulation system for production plant design, steady-state simulation and optimization. It can be used for process simulation and optimization in various fields such as medicine and chemical industry. Aspen Plus does not have a fixed preloaded model, but it can be composed of several unit operating blocks [24, 25]. In Aspen Plus software, the rapid pyrolysis process of biomass can be simulated and the yield of biochar can be predicted [26, 27]. In this study, the simulation is mainly aimed at the yield of biochar. The simulation process is based on the principle that the Gibbs free energy tends to the minimum, and the system composition and phase distribution can be calculated when the chemical equilibrium and phase equilibrium are reached simultaneously $[24,28]$. 


\subsection{Model component specification}

Biomass does not have a unified molecular formula and does not exist in the Aspen Plus database. Therefore, when defining biomass, it needs to be set as an unconventional component, and the simulated global flow is set to MIXCINC. Enthalpy and density are the only attributes calculated for unconventional components, which are calculated by empirical correlation, taking HCOALGEN and DGOALIGT methods as examples [24]. Under this method, industrial analysis and elemental analysis parameters of biomass need to be input into the simulation system. Table 1 lists the component attributes of rice straw and sugarcane bagasse. Since biomass is an unconventional component, it is converted into conventional components cellulose, hemicellulose and lignin in the simulation process. Hemicellulose and cellulose are represented by their monomers $\mathrm{C}_{5} \mathrm{H}_{8} \mathrm{O}_{4}$ (xylan) and $\mathrm{C}_{6} \mathrm{H}_{10} \mathrm{O}_{5}$ (xylose-like cellulose monomer) respectively in the simulation $[24,29]$. Lignin is a three-dimensional network polymer compound composed of phenylpropanes, and its structure is relatively complicated [30, 31]. Faravellia's [32] research has given three representative lignin structures, as shown in Fig. 1. Because rice straw and bagasse belong to the softwood lignin class, the structure of lignin in this study is LIG-C, and its chemical formula is expressed as $\mathrm{C}_{17} \mathrm{H}_{17} \mathrm{O}_{5}$.

Table 1

The component attributes of rice straw and sugarcane bagasse [33]

\begin{tabular}{|llllllllll|}
\hline Biomass & \multicolumn{3}{c|}{ Industrial analysis $(w t \%)$} & \multicolumn{7}{c|}{ Elemental analysis (wt\%) } \\
\cline { 2 - 11 } & Mad & FC & Vm & Ash & C & H & N & S & 0 \\
\hline Rice straw & 7.23 & 1.33 & 45.68 & 45.76 & 26.73 & 4.05 & 1.02 & 0.56 & 66.55 \\
\hline Sugarcane bagasse & 8.52 & 8.12 & 79.45 & 3.91 & 44.31 & 5.73 & 0.63 & $<0.10$ & 49.11 \\
\hline
\end{tabular}

The yield reactor (RYield) in Aspen Plus calculates the material balance and energy balance based on the product distribution. In this reactor, the unconventional components of biomass are converted into conventional components of cellulose, hemicellulose, lignin and ash. The biomass composition of rice straw [34] and sugarcane bagasse [35] are given in Table 2, in which the ash is an inert substance and does not participate in the subsequent reaction process.

Table 2

The biomass composition of rice straw and sugarcane bagasse

\begin{tabular}{|lllll|}
\hline Biomass & $\begin{array}{l}\text { Cellulose } \\
\text { (\%wt) }\end{array}$ & $\begin{array}{l}\text { Hemicellulose } \\
\text { (\%wt) }\end{array}$ & $\begin{array}{l}\text { Lignin } \\
\text { (\%wt) }\end{array}$ & $\begin{array}{l}\text { Ash } \\
(\% w t)\end{array}$ \\
\hline Rice straw & $20 \pm 1$ & $30 \pm 1.2$ & $52 \pm 2$ & $4.9 \pm 1.2$ \\
\hline Sugarcane bagasse & $25 \pm 2.7$ & $48 \pm 2.3$ & $31 \pm 1.2$ & $3.68 \pm 0.46$ \\
\hline
\end{tabular}

\subsection{Reaction process}


Establish a reaction flow chart in Aspen Plus V8.4, as shown in Fig. 2, and the description of a single reaction model is given in Table 3. Biomass and $\mathrm{N}_{2}$ enter the RStoic reactor at the same time, and the feed stream flows are set to $200 \mathrm{~kg} / \mathrm{h}$ and $0.1 \mathrm{kmol} / \mathrm{h}$ respectively [24]. The biomass is dried $\left(100^{\circ} \mathrm{C}\right)$ in the RStoic reactor to remove moisture. Drying process is only the evaporation of the moisture of the biomass raw materials, which is a physical change. The drying process is realized by inputting the reaction equation through the RStoic module and embedding the calculator module. The input reaction equation is: Biomass (wet) $\rightarrow$ Biomass (dry) $+\Phi \mathrm{H}_{2} \mathrm{O}$, the biomass is partially converted into water through this equation, where the conversion rate $\Phi$ is taken as 0.0555 [36]. According to the water mass balance before and after drying and the total mass balance of the feed, a calculator module CONV $1=$ $\left(\mathrm{H}_{2} \mathrm{OIN} 1-\mathrm{H}_{2} \mathrm{ODRY} 1\right) /\left(100-\mathrm{H}_{2} \mathrm{ODRY} 1\right)$ is embedded to control the actual conversion rate of the biomass drying process [37]. Dried biomass stream F-1 enters the RYield reactor, where the unconventional component biomass is converted into conventional components, and the product distribution needs to be set in the RYield reactor. Decomposed stream R-2 enters the RGibbs reactor for pyrolysis. The RGibbs reactor performs pyrolysis of biomass based on the principle of minimizing Gibbs free energy. By changing the temperature of the RGibbs reactor, the relationship between biochar yield and pyrolysis temperature was discussed. The main thermal decomposition temperature ranges of the three components of biomass cellulose, hemicellulose and lignin are $220-315^{\circ} \mathrm{C}, 280-400^{\circ} \mathrm{C}$ and $400-800^{\circ} \mathrm{C}$ respectively [38]. Therefore, in this simulation, the pyrolysis temperature range of the RGibbs reactor is set to $300-800^{\circ} \mathrm{C}$.

Table 3

Reaction model description

\section{Model Description}

RStoic Dry the material to remove the moisture in the biomass before pyrolysis

Flash Based on strict vapor-liquid balance, moisture and biomass materials are separated.

RYield The material balance and energy balance are calculated according to the product distribution, and unconventional components are converted into conventional components.

RGibbs It is the only reactor module that can handle the three-phase equilibrium of vapor, liquid and solid, based on the principle of minimum Gibbs free energy.

Sslip According to the separation of components, the inlet stream is divided into two or more outlet streams.

\subsection{Results discussion}

In the Aspen Plus software, the biochar yield of rice straw and sugarcane bagasse were simulated at different pyrolysis temperatures. As shown in Fig. 3, it can be clearly seen that the biochar yield of rice straw at different temperatures is higher than that of sugarcane bagasse. The reason for the low biochar yield of sugarcane bagasse may be related to the low lignin content in bagasse $[39,40]$. A large number of studies have shown that biomass with higher lignin content and lower cellulose content can obtain 
higher biochar yield. Cellulose and hemicellulose mainly produce volatile substances, and lignin is mainly decomposed into carbon substances [41-44]. The content of lignin in rice straw is as high as $52 \%$, while the content of lignin in sugarcane bagasse is only $31 \%$. Therefore, the biochar yield of rice straw after pyrolysis is significantly higher than that of sugarcane bagasse. In addition, the simulation results also show that as the temperature rises, the biochar yield shows a downward trend, and the biochar yield basically remains unchanged between $300^{\circ} \mathrm{C}-500^{\circ} \mathrm{C}$, and the downward trend is compared when the pyrolysis temperature is higher than $500^{\circ} \mathrm{C}$ obvious. Smets's [45] research shows that the pyrolysis temperature is generally negatively correlated with the biochar yield. When the pyrolysis temperature increases from $400^{\circ} \mathrm{C}$ to $700^{\circ} \mathrm{C}$, the biochar yield decreases by approximately $10 \%-17 \%$. In this study, when the pyrolysis temperature was $300-800^{\circ} \mathrm{C}$, the yield of rice straw biochar decreased by $11.52 \%$, and the yield of sugarcane bagasse biochar decreased by $10.98 \%$. The decrease in biochar yield with increasing temperature is related to the depolymerization of biomass components. Below $500^{\circ} \mathrm{C}$, the devolatilization of biomass slows down, and polycondensation is dominant, so the weight loss is less and the rate of decrease in biochar yield slows down. Zhao [46] and Uchimiya's [47] research also believes that it is reasonable that the yield of biochar has decreased, and that as the temperature continues to rise, the biomass will undergo secondary cracking, volatile substances will be completely decomposed, and more gas will be released to reduce the weight of biochar. In summary, the model established in Aspen Plus is suitable for the pyrolysis reaction of biomass raw materials, and can predict the yield of biochar without the need for experimental data.

Table 4 shows the heat duty of the RGibbs reactor at different pyrolysis temperatures. From the heat duty results, the reaction process of rice straw at $300^{\circ} \mathrm{C}$ and $400^{\circ} \mathrm{C}$ pyrolysis temperature is exothermic reaction, and the reaction process above $500^{\circ} \mathrm{C}$ is endothermic process. As the temperature increases, the more heat energy is required. Sugarcane bagasse is an exothermic reaction only when it is pyrolyzed at $300^{\circ} \mathrm{C}$, and the pyrolysis temperature is higher than $400^{\circ} \mathrm{C}$, which is an endothermic reaction. Comparing the heat duty of the two kinds of biomass pyrolysis, the energy required for the pyrolysis process of sugarcane bagasse is higher than that of rice straw. Considering the pyrolysis of rice straw and sugarcane bagasse to prepare biochar from two aspects of biochar yield and heat duty, rice straw shows obvious advantages.

Table 4

Heat duty of RGibbs reactor

\begin{tabular}{|lllllll|}
\hline & $\mathbf{3 0 0 ^ { \circ } \mathrm { C }}$ & $\mathbf{4 0 0 ^ { \circ } \mathrm { C }}$ & $\mathbf{5 0 0 ^ { \circ } \mathrm { C }}$ & $\mathbf{6 0 0 ^ { \circ } \mathrm { C }}$ & $\mathbf{7 0 0}^{\circ} \mathrm{C}$ & $\mathbf{8 0 0}^{\circ} \mathrm{C}$ \\
\hline Rice straw $(\mathrm{MJ} / \mathrm{h})$ & -706.70 & -366.63 & 222.92 & 1160.90 & 2305.17 & 3119.33 \\
\hline Sugarcane bagasse $(\mathrm{MJ} / \mathrm{h})$ & -281.17 & 61.35 & 664.21 & 1647.90 & 2906.45 & 3828.75 \\
\hline
\end{tabular}

\section{Experimental Study}

\subsection{Material}


On the basis of simulation, the research of this paper conducts experimental research on two kinds of biomass pyrolysis process. Rice straw is obtained directly from farmland, and sugarcane bagasse is obtained from sugarcane purchased from fruit shops through a juicer. Drying the obtained biomass material in a blowing drying oven $\left(50^{\circ} \mathrm{C}\right)$ for $24 \mathrm{~h}$ to remove moisture, then using a high-speed multifunctional pulverizer (Mingxuan 200T, Wuyi Haina Electric Co., Ltd. Zhejiang, China) to pulverize the biomass into fine particles for later use. The untreated and treated biomass is shown in Fig. 4.

\subsection{Biochar production}

The preparation of biochar uses a tube furnace (Hefei Kejing, OTF-1200X-S-VT, Hefei, China) for hightemperature pyrolysis in a nitrogen stream $(15 \mathrm{~mL} / \mathrm{min})$. Setting the heating program of the tube furnace, the heating rate is $5^{\circ} \mathrm{C} / \mathrm{min}$, the temperature is increased from $20^{\circ} \mathrm{C}$ to $300-800^{\circ} \mathrm{C}$ respectively, and keeping at high temperature for $120 \mathrm{~min}$ [48]. Weigh $1 \mathrm{~g}$ of biomass evenly in a quartz boat, and push the quartz boat into the tube furnace for pyrolysis process. After the reaction, the tube furnace is naturally cooled to room temperature, and the reactant biochar is taken out. Using Eq. 1 to calculate the biochar yield. The yields of pyrolysis of rice straw and sugarcane bagasse to production biochar at different temperatures are given in Table 5.

Equation 1 Yield $=m_{b c} / m_{b} \times 100 \%$,

$m_{b c}(g)$ is the quality of biochar, and $m_{b}(1 \mathrm{~g})$ is the quality of biomass raw materials.

Table 5

The yield of biochar at different pyrolysis temperatures

\begin{tabular}{|c|c|c|c|c|c|c|c|}
\hline & & $300^{\circ} \mathrm{C}$ & $400^{\circ} \mathrm{C}$ & $500^{\circ} \mathrm{C}$ & $600^{\circ} \mathrm{C}$ & $700^{\circ} \mathrm{C}$ & $800^{\circ} \mathrm{C}$ \\
\hline \multirow[t]{3}{*}{ Rice straw } & $\begin{array}{l}\text { Experimental value } \\
(\%)\end{array}$ & 50.63 & 53.27 & 45.42 & 35.46 & 33.56 & 33.19 \\
\hline & $\begin{array}{l}\text { Simulation } \\
\text { value (\%) }\end{array}$ & 52.50 & 52.24 & 51.28 & 48.57 & 44.01 & 40.98 \\
\hline & $\begin{array}{l}\text { Difference } \\
\text { value (\%) }\end{array}$ & 1.87 & 1.03 & 5.86 & 13.11 & 10.45 & 7.79 \\
\hline \multirow[t]{3}{*}{$\begin{array}{l}\text { Sugarcane } \\
\text { bagasse }\end{array}$} & $\begin{array}{l}\text { Experimental value } \\
(\%)\end{array}$ & 42.50 & 41.20 & 37.00 & 30.73 & 28.93 & 26.71 \\
\hline & $\begin{array}{l}\text { Simulation } \\
\text { value (\%) }\end{array}$ & 41.29 & 41.75 & 41.84 & 39.66 & 34.36 & 30.32 \\
\hline & $\begin{array}{l}\text { Difference } \\
\text { value (\%) }\end{array}$ & 1.21 & 0.55 & 4.84 & 8.93 & 5.43 & 3.61 \\
\hline
\end{tabular}


In Table 5, we see that as the pyrolysis temperature increases, the biochar yield shows a downward trend, which is consistent with the simulation results. At different pyrolysis temperatures, there is a certain difference between the experimental value and the simulated value of biochar which is maintained between $0.55 \%$ and $13.11 \%$. The difference between the experimental value and the simulated value is small between $300-500^{\circ} \mathrm{C}$, and the difference between $600-800^{\circ} \mathrm{C}$ is large, which can also indicate that the pyrolysis decomposition or secondary cracking process of biomass at higher temperatures is more complicated. The experimental value is close to the simulated value, which verifies that the pyrolysis model established in Aspen Plus in this study is feasible. Under the condition of not needing to do pyrolysis experimental, only need to measure the content of cellulose, hemicellulose and lignin in the biomass, and the output of biochar and its optimal pyrolysis temperature can be predicted through software simulation.

In order to further understand the morphological changes of biomass in the process of converting biomass into biochar, three different temperatures $\left(300^{\circ} \mathrm{C}, 500^{\circ} \mathrm{C}, 700^{\circ} \mathrm{C}\right)$ of rice straw biochar and sugarcane bagasse biochar were selected for characterization and analysis. The SEM (scanning electron microscope) analysis of rice straw and sugarcane bagasse biochar at different temperatures are shown in Figs. 5 and 6, respectively. From the two figures, we can clearly see that as the temperature increases, the pores of biochar gradually become larger and the wall surface becomes thinner. At $300^{\circ} \mathrm{C}$, biochar showed slight cracks, and at $500^{\circ} \mathrm{C}$, obvious cracks appeared. When the temperature is as high as $700^{\circ} \mathrm{C}$, the pore walls of the biochar are destroyed and collapsed, indicating that the biochar has undergone secondary rupture at high temperatures. Comparing the structures of the two biochar, sugarcane bagasse exhibits poor high temperature resistance. At $500^{\circ} \mathrm{C}$, the pore walls of sugarcane bagasse biochar have become very thin, and at $700^{\circ} \mathrm{C}$, the debris is more obvious.

The XRD analysis of rice straw biochar and sugarcane bagasse biochar are shown in Fig. 7. In general, different carbonization temperatures and different biochar have similar diffraction peaks. There are relatively broad and gentle diffuse diffraction peaks between $2 \theta=18^{\circ}-27^{\circ}$. With the increase of carbonization temperature, the peak position of the diffraction peaks moves toward a higher angle. At the same time, the peak intensity of the diffraction peak increases and the peak area increases. It indicates that increasing temperature will shrink the spacing of the cellulose graphite microcrystalline layers in the biochar, increase the amount of formation and crystallinity, and transform into more stable carbon compounds, thus playing the role of carbon sequestration and increase [49]. However, there are still some subtle changes in the biochar XRD map. In Fig. 7(a), there are some sharp diffraction peaks in the spectrum. These diffraction peaks are mainly inorganic crystals in rice straw, including $\mathrm{SiO}_{2}, \mathrm{KCl}$ and

$\mathrm{CaCO}_{3}$, etc., which are related to the high content of $\mathrm{Si}$ and $\mathrm{K}$ in rice straw [50]. In comparison, there are no such sharp diffraction peaks in Fig. 7(b), indicating that there are less inorganic substances in sugarcane bagasse.

\section{Economic Analysis}

In the process of biomass pyrolysis, in addition to biochar, there are bio-tar and pyrolysis gas. Bio-tar and pyrolysis gas are usually used as the main products of biomass pyrolysis, and they are widely studied 
and applied because of their energy value, while biochar is usually regarded as a by-product. In fact, biochar has a wide range of applications. Technical and economic studies have shown that if biochar is not regarded as an important product, the economic competitiveness of biomass pyrolysis is not strong. Alhashimi et al. [51] compared the economic performance of biochar and activated carbon as adsorbents. The average cost of biochar and activated carbon was $5 \mathrm{USD} / \mathrm{kg}$ and $5.6 \mathrm{USD} / \mathrm{kg}$, respectively. The author also collected the prices of biochar prepared from different biomass raw materials in different countries, ranging from 0.8-18 USD $/ \mathrm{kg}$. Harsono et al. [52] analyzed the economics of biomass carbon produced from palm oil empty fruit bunches, and the results showed that only when the price of biochar is higher than 533 USD/t, can biochar be profitable. From the perspective of farmers, Abbie Clare et al. [53] studied the microeconomics and social applicability of biochar in four agricultural systems. The results show that the biochar produced by small-scale farmers does not have an economic competitive advantage in China. If the application of biochar is expanded to other system products, China's biochar industry will undoubtedly have potential. The cost of biochar varies greatly in different countries, and there are relatively few economic studies on large-scale production of biochar in China. Therefore, it is necessary to analyze the biochar economy through the LCC (Life Cycle Cost) method to provide a reference for China's biochar market pricing. In the LCC system, cost input includes raw materials, electricity, manual labor, land and equipment, etc. The system boundary diagram is shown in Fig. 8.

In the process of calculating biochar economy, using $1 \mathrm{t}$ of biomass as raw material, the pyrolysis temperature of biomass is $400^{\circ} \mathrm{C}$, and the biochar yields of rice straw and sugarcane 'bagasse are $53.27 \%$ and $41.20 \%$, respectively. The price of rice straw comes from Jiangsu Province, the price is 0.04 USD $/ \mathrm{kg}$, that is, the cost of $1 \mathrm{t}$ of rice straw is 40 USD [53]. The price of sugarcane bagasse comes from Yunnan Province, referring to the price $440 \mathrm{RMB} / \mathrm{t}$ given on the Alibaba website, that is, the cost of $1 \mathrm{t}$ of sugarcane bagasse is 67.18 USD ( 1 USD $=6.5491 \mathrm{RMB}$ ). The reference price of $\mathrm{N}_{2}$ comes from ChangZhouShi SaiFu Special gas co., LTD. Electricity mainly includes biomass drying, grinding and pyrolysis processes, as well as daily electricity consumption. The price of electricity refers to 0.6 $\mathrm{RMB} / \mathrm{kW} \cdot \mathrm{h}$ given by China Power Grid. The consumption of diesel is used in the process of biomass collection and product transportation. The transportation distance is assumed to be $20 \mathrm{~km}$, and the fuel consumption of the truck is $0.0482 \mathrm{~L} /(\mathrm{t} \cdot \mathrm{km})$, referring to the average price of diesel in the local gas station in the past 15 days. The cost of land and equipment is a fixed cost, referring to the biochar plant in Selangor, Malaysia [52], the investment in fixed assets is 170.23 USD/yr. If this cost is evenly divided into months or days, the cost of land and equipment will be lower. The total cost of preparing biochar with $1 \mathrm{t}$ of rice straw and sugarcane bagasse as raw materials are 413.52 and 440.70 USD, respectively. The specific data are given in Table 6. 
Table 6

The cost of biochar ( $1 \mathrm{t}$ biomass material)

\begin{tabular}{|llllllll|}
\hline & Biomass & $\mathbf{N}_{\mathbf{2}}$ & Electricity & Diesel & Human & $\begin{array}{l}\text { Land and } \\
\text { equipment }\end{array}$ & Total \\
\hline Rice straw (USD) & 40 & 12.22 & 4.03 & 3.81 & 183.23 & 170.23 & 413.52 \\
\hline $\begin{array}{l}\text { Sugarcane bagasse } \\
\text { (USD) }\end{array}$ & 67.18 & 12.22 & 4.03 & 3.81 & 183.23 & 170.23 & 440.70 \\
\hline 1 USD = 6.5491 RMB (December 23, 2020 exchange rate) & & & & \\
\hline
\end{tabular}

According to the biochar yield at $400^{\circ} \mathrm{C}$, the unit prices of rice straw biochar and sugarcane bagasse biochar are 0.79 and $0.93 \mathrm{USD} / \mathrm{kg}$, respectively. The cost of sugarcane bagasse biochar is slightly higher than that of rice straw, mainly because the purchase cost of sugarcane bagasse is slightly higher, and the yield of biochar is lower. Compared with the biochar price of 0.8-18 USD $/ \mathrm{kg}$ given by Alhashimi et al. [51], the biochar cost studied in this paper is relatively low, especially for rice straw biochar. Although the cost of biochar in this study is higher than the cost of 533 USD/t given in the results of Harsono et al. [52], it is not much higher, and the cost of land and equipment in this study is calculated on an annual basis. If this part of the cost is subtracted, it is believed that the cost of rice straw and sugarcane bagasse biochar will be lower. We should also note that the bio-tar and pyrolysis gas produced by biomass pyrolysis can also be collected as energy products. These products can also bring certain economic benefits, and to a certain extent can effectively reduce the economic cost of biomass pyrolysis.

\section{Conclusion}

The widespread application of biochar and the increasing awareness of environmental protection make people pay more attention to the process of preparing biochar from biomass pyrolysis. The yield of biochar is most affected by the pyrolysis temperature. Aspen Plus V8.4 software was used to simulate the pyrolysis process of rice straw and sugarcane bagasse. The biochar production at $300^{\circ} \mathrm{C}, 400^{\circ} \mathrm{C}$, $500^{\circ} \mathrm{C}, 600^{\circ} \mathrm{C}, 700^{\circ} \mathrm{C}$ and $800^{\circ} \mathrm{C}$ temperatures were simulated, and the results showed that as the temperature increased, the biochar yield showed a downward trend. Below $500^{\circ} \mathrm{C}$, the downward trend is relatively gentle, when the temperature is higher than $500^{\circ} \mathrm{C}$, the downward trend is more obvious. This is due to the secondary cracking of biochar to produce more pyrolysis gas at higher temperatures. At the same time, the heat duty of the RGibbs reactor at different pyrolysis temperatures was compared. Rice straw is an exothermic reaction at $300^{\circ} \mathrm{C}, 400^{\circ} \mathrm{C}$, and an endothermic reaction when the pyrolysis temperature is higher than $500^{\circ} \mathrm{C}$. Sugarcane bagasse is an exothermic reaction only at $300^{\circ} \mathrm{C}$, and an endothermic reaction when the pyrolysis temperature is higher than $400^{\circ} \mathrm{C}$. Comparing the two biomasses, rice straw requires less heat energy during the pyrolysis process and can generate more biochar.

Based on the simulation, a tube furnace was used to pyrolyze rice straw and sugarcane bagasse. There is a certain difference between the experimental value and the simulated value of biochar yield, but the difference is not large, especially the difference at lower temperature, which is maintained within $6 \%$. This 
further proves that the pyrolysis model built in Aspen Plus software is feasible. Without experimentation, the biochar production and the optimal pyrolysis temperature can be predicted by measuring the components of biomass. Characterization and analysis of some rice straw biochar showed that as the temperature increased, the pore structure of biochar became more abundant and the pore size became larger. However, when the temperature is higher than $700^{\circ} \mathrm{C}$, the cracks on the surface of the biochar begin to decrease, and the pore structure of the biochar appears to be broken. This reasonably explains that the biochar will undergo secondary cracking at excessively high temperatures, which greatly reduces the biochar yield.

Finally, the biochar economy is analyzed, and the results show that the cost of rice straw and sugarcane bagasse biochar are 0.79 and $0.93 \mathrm{USD} / \mathrm{kg}$, respectively. This cost has a relatively large economic competitive advantage in the biochar industry. Comparing with sugarcane bagasse, rice straw has obvious advantages. The yield of biochar is higher, the pyrolysis process requires less heat energy, and the cost is lower. In short, the production of biochar from biomass in China is a technically feasible and economically feasible project, and the government has also supported the construction of multiple largescale biomass pyrolysis plants. In addition, the obtained biochar resources can be used as soil organic fertilizer to return to farmland, and can also be used as catalyst carriers, lithium-ion batteries and other fields. Undoubtedly, biochar has great potential in the future energy development process.

\section{Declarations}

\section{Conflicts of interests}

The authors declare no conflict of interest.

\section{Acknowledgements}

We acknowledge the financial supports from Universities Natural Science Research of Jiangsu Province (20KJB480009).

\section{References}

[1] Doula, M., K., Sarris, A., Hliaoutakis, A., Kydonakis, A., Papadopoulos, N.S., Argyriou, L.: Building a strategy for soil protection at local and regional scale-the case of agricultural wastes landspreading. Environ. Monit. Assess. 188, 141 (2016). https://doi.org/10.1007/s10661-016-5139-0.

[2] Abnisa, F., Wan Daud, W.M.A.: A review on co-pyrolysis of biomass: An optional technique to obtain a high-grade pyrolysis oil. Energy Convers. Manage. 87, 71-85 (2014). https://doi.org/10.1016/j.enconman.2014.07.007. 
[3] Liu, Z., Zhou, X., Chen, X., Dai, C., Zhang, J., Zhang Y.: Biosorption of clofibric acid and carbamazepine in aqueous solution by agricultural waste rice straw. J. Environ. Sci. 25, 2384-2395 (2013). https://doi.org/10.1016/S1001-0742(12)60324-6.

[4] Arregi, A., Amutio, M., Lopez, G., Bilbao, J., Olazar, M.: Evaluation of thermochemical routes for hydrogen production from biomass: A review. Energy Convers. Manage. 165, 696-719 (2018). https://doi.org/10.1016/j.enconman.2018.03.089.

[5] Yan, N., Chen, X.: Don't waste seafood waste. Nature 524, 155-157 (2015). https://doi.org/10.1038/524155a.

[6] Nzihou, A.: Biochar from biomass and waste. Waste Biomass Valori. 1, 177-189 (2010). https://doi.org/10.1007/s12649-010-9024-8.

[7] Deng, L., Zhong, W., Wang, J., Zhang, P., Fang, H., Yao, L., Liu, X., Ren, X., Li, Y.: The enhancement of electrochemical capacitance of biomass-carbon by pyrolysis of extracted nanofibers. Electrochimica Acta 228, 398-406 (2017). https://doi.org/10.1016/j.electacta.2017.01.099.

[8] Imtiaz, S., Zhang, J., Zafar, Z.A., Ji, S., Huang, T., Anderson, J.A., Zhang, Z., Huang, Y.: Biomass-derived nanostructured porous carbons for lithium-sulfur batteries. Sci. China Mater. 59, 389-407 (2016). https://doi.org/10.1007/s40843-016-5047-8.

[9] Bird, M.I., Wurster, C.M., Silva, P.H.D.P., Bass, A.M., Nys, R.D.: Algal biochar-production and properties. Bioresour. Technol. 102, 1886 (2011). https://doi.org/10.1016/j.biortech.2010.07.106.

[10] Liang, B., Lehmann, J., Solomon, D., Kinyangi, J., Grossman, J., O"Neill, B., Skjemstad, J.O., Thies, J., LuizO, F.J., Petersen, J.: Black carbon increases cation exchange capacity in soils. Soil Sci. Soc. Am. J. 70, 1719-1730 (2006). https://doi.org/10.2136/sssaj2005.0383.

[11] Lin, X.W., Xie, Z.B., Zheng, J.Y., Liu, Q., Bei, Q.C., Zhu, J.G.: Effects of biochar application on greenhouse gas emissions, carbon sequestration and crop growth in coastal saline soil. Eur. J. Soil Sci. 66, 329-338 (2015). https://doi.org/10.1111/ejss.12225.

[12] Li, Y., Hu, H., Song, J., Wu, Y., Chen, Y.: An excellent Fe, N Co-Doped porous biomass carbon oxygen reduction reaction electrocatalyst: Effect of Zinc-based activators on catalytic activity. Energy Technol. 80, 96-104 (2020). https://doi.org/10.1002/ente.202000625.

[13] Hou, J., University, T.R.: Study on the acid-reducing effect of biomass carbon on acid soil in new zanthoxylum orchard. Anhui Agricultural Ence Bulletin 25, 106-107 (2019). https://doi.org/10.16377/j.cnki.issn1007-7731.2019.11.044.

[14] Plaza, M.G., García, S., Rubiera, F., Pis, J.J., Pevida, C.: Evaluation of ammonia modified and conventionally activated biomass based carbons as $\mathrm{CO}_{2}$ adsorbents in postcombustion conditions. Sep. 
Purif. Technol. 80, 96-104 (2011). https://doi.org/10.1016/j.seppur.2011.04.015.

[15] Xu, X., Meng, Z., Zhu, X., Zhang, S., Han, W.Q.: Biomass carbon composited FeS2 as cathode materials for high-rate rechargeable lithium-ion battery. J. Power Sources $\mathbf{3 8 0}, 12-17$ (2018). https://doi.org/10.1016/j.jpowsour.2018.01.057.

[16] Xiao, L., Xianqing, Z., Xian, L., Zong, Z., Ryuichi, A.: Effect of pressurized torrefaction pretreatments on biomass $\mathrm{CO}_{2}$ gasification. Energy Fuels 29, 1485 (2015).

https://doi.org/10.1021/acs.energyfuels.5b01485.

[17] Zhang, L., Xu, C., Champagne, P.: Overview of recent advances in thermo-chemical conversion of biomass. Energy Convers. Manage. 51, 969-982 (2010). https://doi.org/10.1016/j.enconman.2009.11.038.

[18] Gaskin, J.W., Steiner, C., Harris, K., Das, K.C., Bibens, B.: Effect of low-temperature pyrolysis conditions on biochar for agricultural use. Trans. Asabe 51, 2061-2069

(2008). https://doi.org/10.13031/2013.25409.

[19] Singh, B., Singh, B.P., Cowie, A.L.: Characterisation and evaluation of biochars for their application as a soil amendment. Soil Res. 48, 516-525 (2010). https://doi.org/10.1071/SR10058.

[20] Choi, H.S., Choi, Y.S., Park, H.C.: Fast pyrolysis characteristics of lignocellulosic biomass with varying reaction conditions. Renew. Energy 42, 131-135 (2012). https://doi.org/10.1016/j.renene.2011.08.049.

[21] Cao, J., Xiao, G., Xu, X., Jin, B.S.: Functional groups evolvement and charcoal formation during lignin pyrolysis/carbonization. J. Southeast Univ. (Engl. Ed.) 42, 83-87 (2012).

https://doi.org/10.3969/j.issn.1001-0505.2012.01.016.

[22] Kazmerski, L.: Renewable and Sustainable Energy Reviews. Renew. Sust. Energ. Rev. 38, 834-847 (2016). https://doi.org/10.1016/j.rser.2014.07.023.

[23] Chen, B., Zhou, D., Zhu, L.: Transitional adsorption and partition of nonpolar and polar aromatic contaminants by biochars of pine needles with different pyrolytic temperatures. Environ. Sci. Technol. 42, 5137-5143 (2008). https://doi.org/10.1021/es8002684.

[24] Adeniyi, A.G., Ighalo, J.O., Aderibigbe, F.A.: Modelling of integrated processes for the pyrolysis and steam reforming of rice husk (Oryza sativa). SN Appl. Sci. 1, 841 (2019). https://doi.org/10.1007/s42452019-0877-6.

[25] Ward, J., Rasul, M.G., Bhuiya, M.M.K.: Energy recovery from biomass by fast pyrolysis. Procedia Eng. 90, 669-674 (2014). https://doi.org/10.1016/j.proeng.2014.11.791.

[26] Adeniyi, A.G., Ighalo, J.O., Amosa, M.K.: Modelling and simulation of banana (Musa spp.) waste pyrolysis for bio-oil production. Biofuels 1-5 (2019). https://doi.org/10.1080/17597269.2018.1554949. 
[27] Adeniyi, A.G., Ighalo, J.O., Abdulsalam, A.: Modeling of integrated processes for the recovery of the energetic content of sugar cane bagasse. Biofuels Bioprod. Biorefin. 13, 1-11 (2019). https://doi.org/10.1002/bbb.1998.

[28] Adeniyi, A.G., Otoikhian, K.S., Ighalo, J.O.: Steam reforming of biomass pyrolysis oil: A review. Int. J. Chem. Reactor Eng. 17, (2019). https://doi.org/10.1515/ijcre-2018-0328.

[29] Peters, J.F., Iribarren, D., Dufour, J.: Predictive pyrolysis process modelling In Aspen Plus. European Biomass Conference and Exhibition. 2014.

[30] Yu, C., Wen-Ran, H., Lin, F.: Progress in the structure of lignin and its analyzing methods. Polymer Bull. 3, 8-13 (2012). https://doi.org/10.14028/j.cnki.1003-3726.2012.03.011.

[31] Zhang, Y., Ye, Y.Y., Fan, J., Chang, J.: Selective production of phenol, guaiacol and 2,6dimethoxyphenol by alkaline hydrothermal conversion of lignin. J. Biobased Mater. Bioenergy 7, 696-701 (2013). https://doi.org/10.1166/jbmb.2013.1397.

[32] Faravelli, T., Frassoldati, A., Migliavacca, G., Ranzi, E.: Detailed kinetic modeling of the thermal degradation of lignins. Biomass Bioenerg. 34, 290-301 (2010). https://doi.org/10.1016/j.biombioe.2009.10.018.

[33] Titiloye, J.O., Abu Bakar, M.S., Odetoye, T.E.: Thermochemical characterisation of agricultural wastes from West Africa. Ind. Crops Prod. 47, 199-203 (2013). https://doi.org/10.1016/j.indcrop.2013.03.011.

[34] Zhu, Z., Liu, Y., Gomez, L.D., Wei, T., Macquarrie, D.J.: Thermochemical pretreatments of maize stem for sugar recovery: comparative evaluation of microwave and conventional heating. Ind. Crops Prod. 160, (2020). https://doi.org/10.1016/j.indcrop.2020.113106.

[35] Zhu, Z., Liu, Y., Yang, X., Mcqueen-Mason, S.J., Macquarrie, D.J.: Comparative evaluation of microwave-assisted acid, alkaline, and inorganic salt pretreatments of sugarcane bagasse for sugar recovery. Biomass Convers. Biorefin. 8, 680-687 (2020). https://doi.org/10.1007/s13399-020-00680-7.

[36] Na, L., Xue, H.: Simulation and calculation for coal drying process by Aspen Plus. Coal Convers. 36, 65-67 (2013). https://doi.org/10.19726/j.cnki.ebcc.2013.01.015.

[37] Burlington, M.: Getting Started Modeling Processes with Solids. Aspen Technology (2010).

[38] Yang, H., Yan, R., Chen, H., Lee, D.H., Zheng, C.: Characteristics of hemicellulose, cellulose and lignin pyrolysis. Fuel 86, 1781-1788 (2007). https://doi.org/10.1016/j.fuel.2006.12.013.

[39] Oasmaa, A., Solantausta, Y., Arpiainen, V., Kuoppala, E., Sipila, K.: Fast pyrolysis bio-oils from wood and agricultural residues. Energy Fuels 24, 1380-1388 (2010). https://doi.org/10.1021/ef901107f. 
[40] Tan, S.W.H., Luo, Z.Y., Jiang, Y.C., Cen, K.F.: Experimental study of lignin flash pyrolysis. J. Zhejiang Univ. (Eng. Sci.) 39, 710-714 (2005). https://doi.org/10.1016/j.molcatb.2005.02.001.

[41] Wang, H., Wang, X., Cui, Y., Xue, Z., Ba, Y.: Slow pyrolysis polygeneration of bamboo (Phyllostachys pubescens): Product yield prediction and biochar formation mechanism. Bioresour. Technol. 263, 1906519078 (2018). https://doi.org/10.1016/j.biortech.2018.05.040.

[42] Lin, X.Q., Lu, H.H., Liu, Y.X., Wang Y.Y., Yang, S.M.: Effects of biomass and carbonization temperature on biochar yield and characteristics. Acta Agric. Univ. Zhejiang 39, 710-714 (2016). https://doi.org/10.3969/j.issn.1004-1524.2016.07.18.

[43] Mok, W.S.L., Antal, M.J., Szabo, P., Varhegyi, G., Zelei, B.: Formation of charcoal from biomass in a sealed reactor. Ind. Eng. Chem. Res. 31, 1162-1166 (1992). https://doi.org/10.1021/ie00004a027.

[44] Besler, S.: The pyrolysis of rice husks in a thermogravimetric analyser and static batch reactor. Fuel 72, 151-159 (1993). https://doi.org/10.1016/0016-2361(93)90391-E.

[45] Smets, K., Roukaerts, A., Czech, J., Reggers, G., Schreurs, S., Carleer, R., Yperman, J.: Slow catalytic pyrolysis of rapeseed cake: product yield and characterization of the pyrolysis liquid. Biomass Bioenerg. 57, 180-190 (2013). https://doi.org/10.1016/j.biombioe.2013.07.001.

[46] Zhao, B., O'Connor, D., Zhang, J., Peng, T., Zheng, T.: Effect of pyrolysis temperature, heating rate, and residence time on rapeseed stem derived biochar. J. Cleaner Prod. 174, 977-987 (2018). https://doi.org/10.1016/j.jclepro.2017.11.013.

[47] Uchimiya, M., Wartelle, L.H., Klasson, K.T., Fortier, C.A., Lima, I.M.: Influence of pyrolysis temperature on biochar property and function as a heavy metal sorbent in soil. J. Agric. Food Chem. 59, 2501-2510 (2011). https://doi.org/10.1021/jf104206c.

[48] Demirbas, A., Arin, G.N.: An overview of biomass pyrolysis. Energ. Source. 24, 475-482 (2002). https://doi.org/10.1016/s0140-6701(03)83069-2.

[49] Zheng, Z.W., Chen, B.G., Liu, G.F., Zhao, J.: Analysis of XRD spectral structure and carbonization of the biochar preparation. Spectrosc. Spectral Anal. 36, 3355-3359

(2016). https://doi.org/10.3964/j.issn.1000-0593(2016)10-3355-05.

[50] Cuiping, L., Chuangzhi, W., Yan, Y., Haitao, H.: Chemical elemental characteristics of biomass fuels in China. Biomass Bioenerg. 27, 119-130 (2004). https://doi.org/10.1016/j.biombioe.2004.01.002.

[51] Alhashimi, H.A., Aktas, C.B.: Life cycle environmental and economic performance of biochar compared with activated carbon: A meta-analysis. Resour. Conserv. Recycl. 118, 13-26 (2017). https://doi.org/10.1016/j.resconrec.2016.11.016. 
[52] Harsono, S.S., Grundman, P., Lau, L.H., Hansen, A., Salleh, M.A.M., Meyer-Aurich, A., Idris, A., Ghazi, T.I.M.: Energy balances, greenhouse gas emissions and economics of biochar production from palm oil empty fruit bunches. Resour. Conserv. Recycl. 77, 108-115 (2013). https://doi.org/10.1016/j.resconrec.2013.04.005.

[53] Abbie, C., Andrew, B., John, M.D., Simon, S., From rhetoric to reality: farmer perspectives on the economic potential of biochar in China. Int. J. Agr. Sustain. 12, 440-458 (2014). https://doi.org/10.1080/14735903.2014.927711.

\section{Figures}<smiles>[R]c1ccc(OC(C(O)C(C)=O)C(O)c2ccc(O)cc2)cc1</smiles>

LIG-C $\mathrm{C}_{17} \mathrm{H}_{17} \mathrm{O}_{5}$

$(67.8 \% \mathrm{C} 5.6 \% \mathrm{H} 26.6 \% \mathrm{O})$<smiles>[R]c1cc(OC)c(OC(CO)C(O)(C(=O)O)c2cc(OC)c(O)c(OC)c2)c(OC)c1</smiles>

LIG-O $\mathrm{C}_{16} \mathrm{H}_{11} \mathrm{O}_{6}\left(\mathrm{OCH}_{3}\right)_{4}$

$(56.7 \% \mathrm{C} 5.4 \% \mathrm{H} 37.8 \% \mathrm{O})$<smiles>[R]c1cc(OC)c(OC(CO)C(O)(c2cc(OC)c(O)c(OC)c2)C(C)C)c(OC)c1</smiles>

LIG-H $\mathrm{C}_{18} \mathrm{H}_{17} \mathrm{O}_{5}\left(\mathrm{OCH}_{3}\right)_{4}$

$(60.4 \% \mathrm{C} 6.6 \% \mathrm{H} 33.0 \% \mathrm{O})$

\section{Figure 1}

Different types of lignin structure

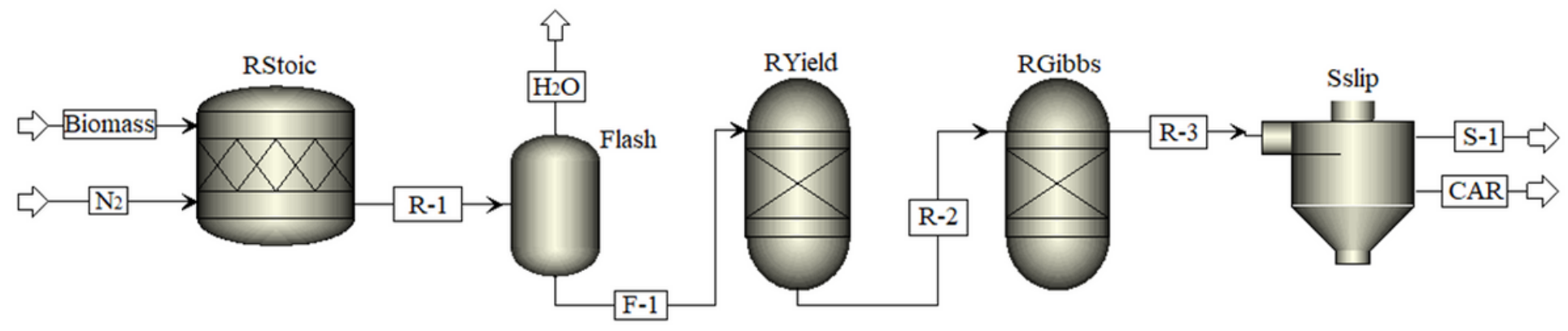

Figure 2

Flow chart of biomass pyrolysis 


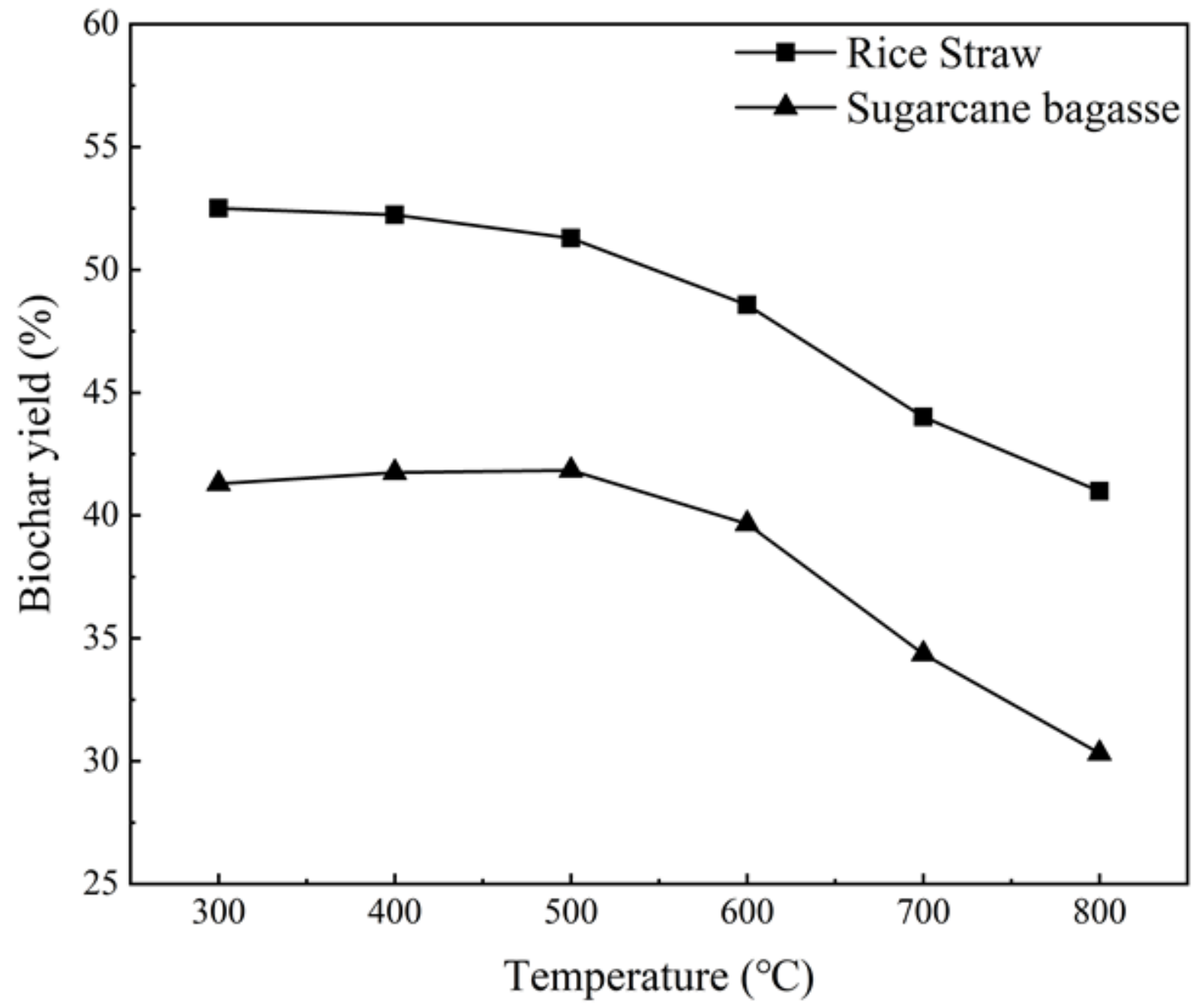

Figure 3

The effect of different pyrolysis temperature on biochar yield 
(a)

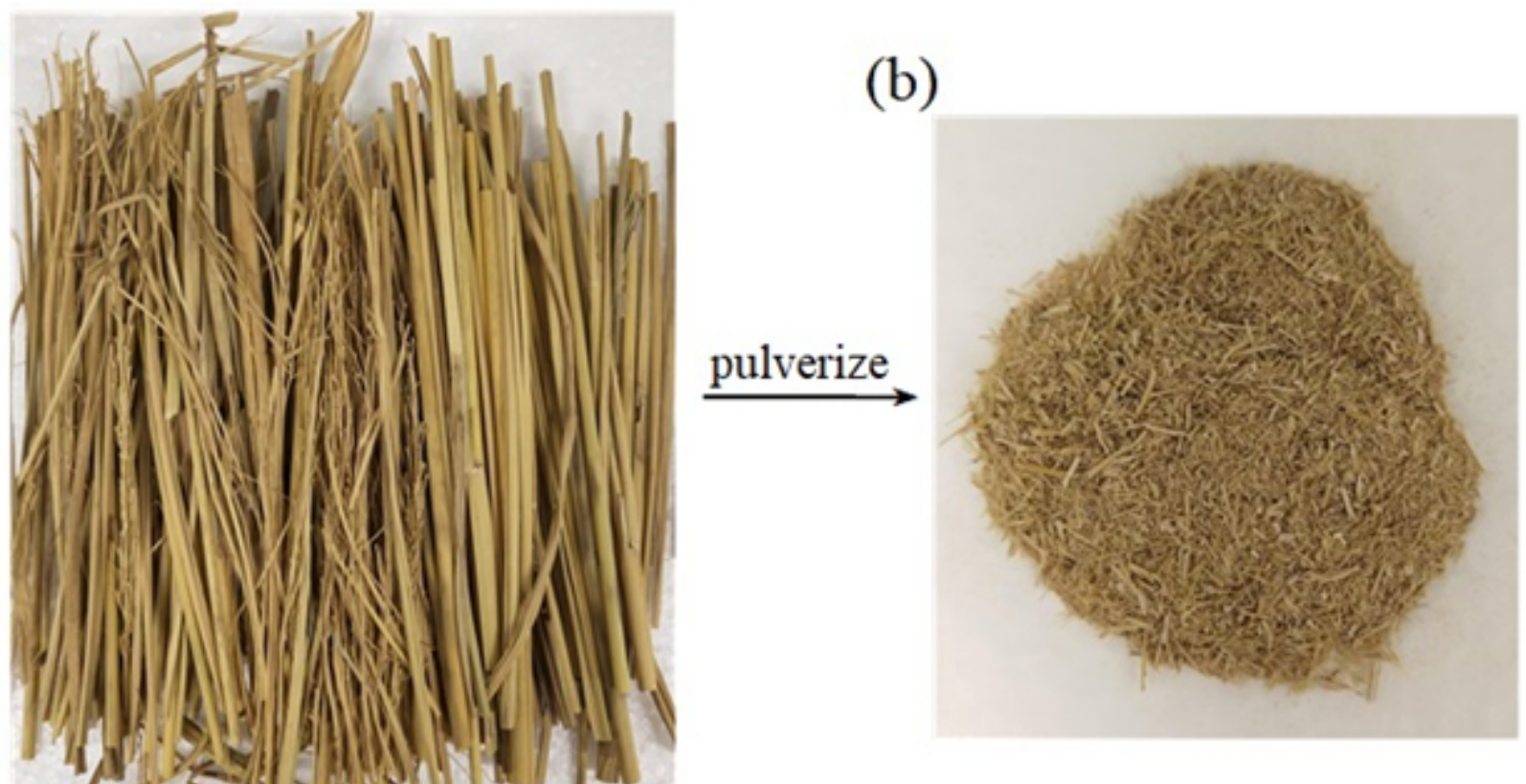

(c)

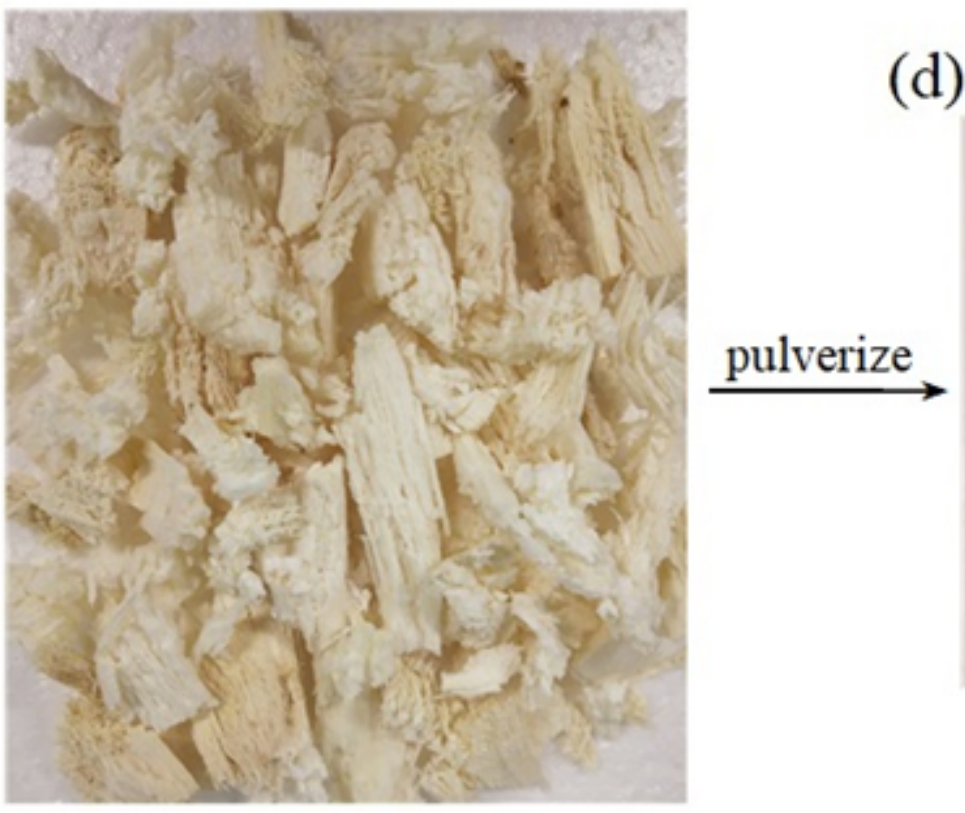

(d)

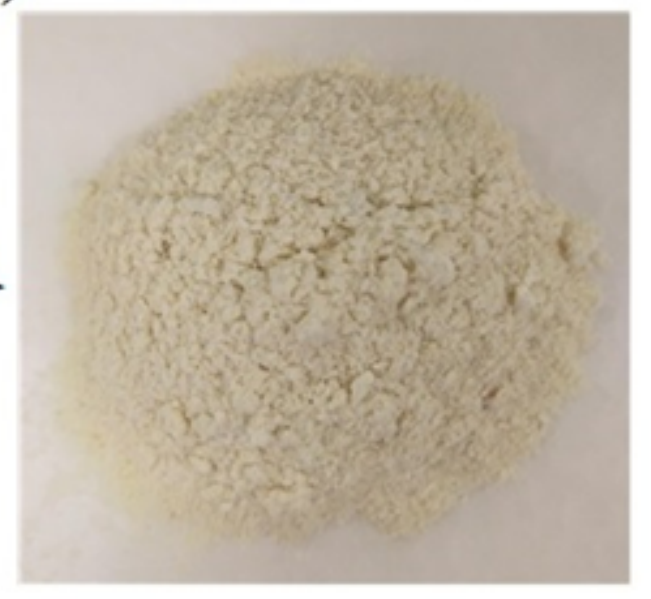

Figure 4

(a) untreated rice straw, (b) dry and pulverize rice straw, (c) untreated sugarcane bagasse, (d) dry and pulverize sugarcane bagasse
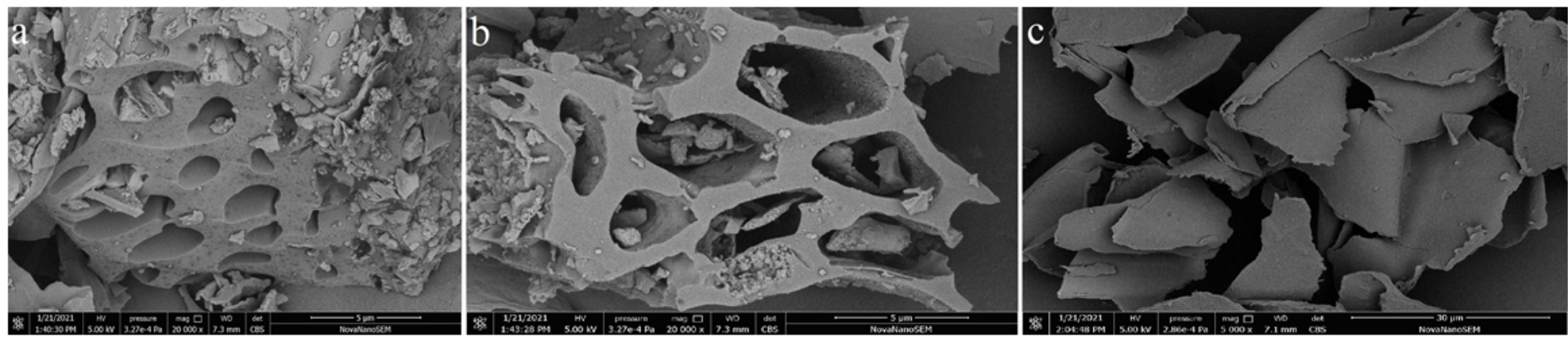


\section{Figure 5}

Rice straw biochar, (a) $300^{\circ} \mathrm{C}$, (b) $500^{\circ} \mathrm{C}$, (c) $700^{\circ} \mathrm{C}$
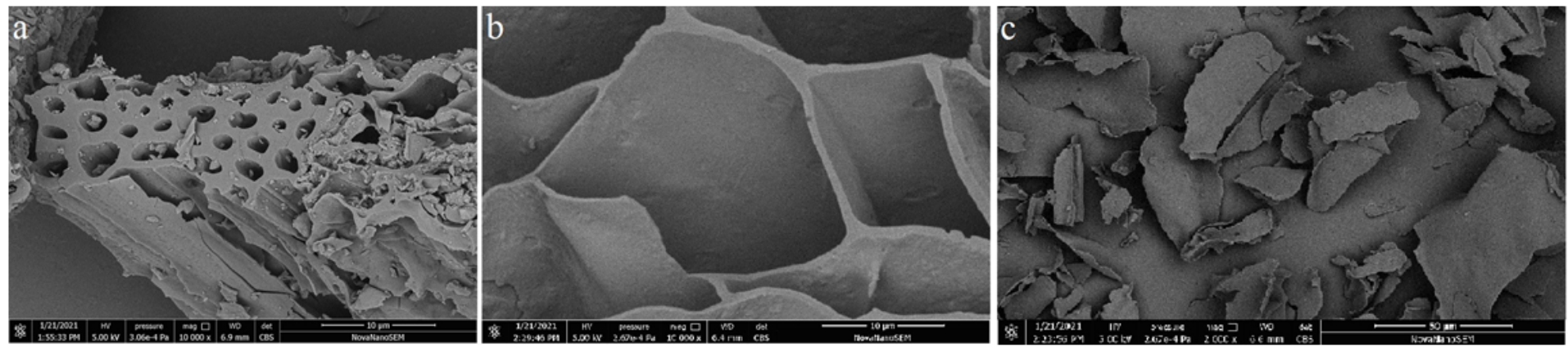

Figure 6

Sugarcane bagasse biochar, (a) $300^{\circ} \mathrm{C}$, (b) $500^{\circ} \mathrm{C}$, (c) $700^{\circ} \mathrm{C}$
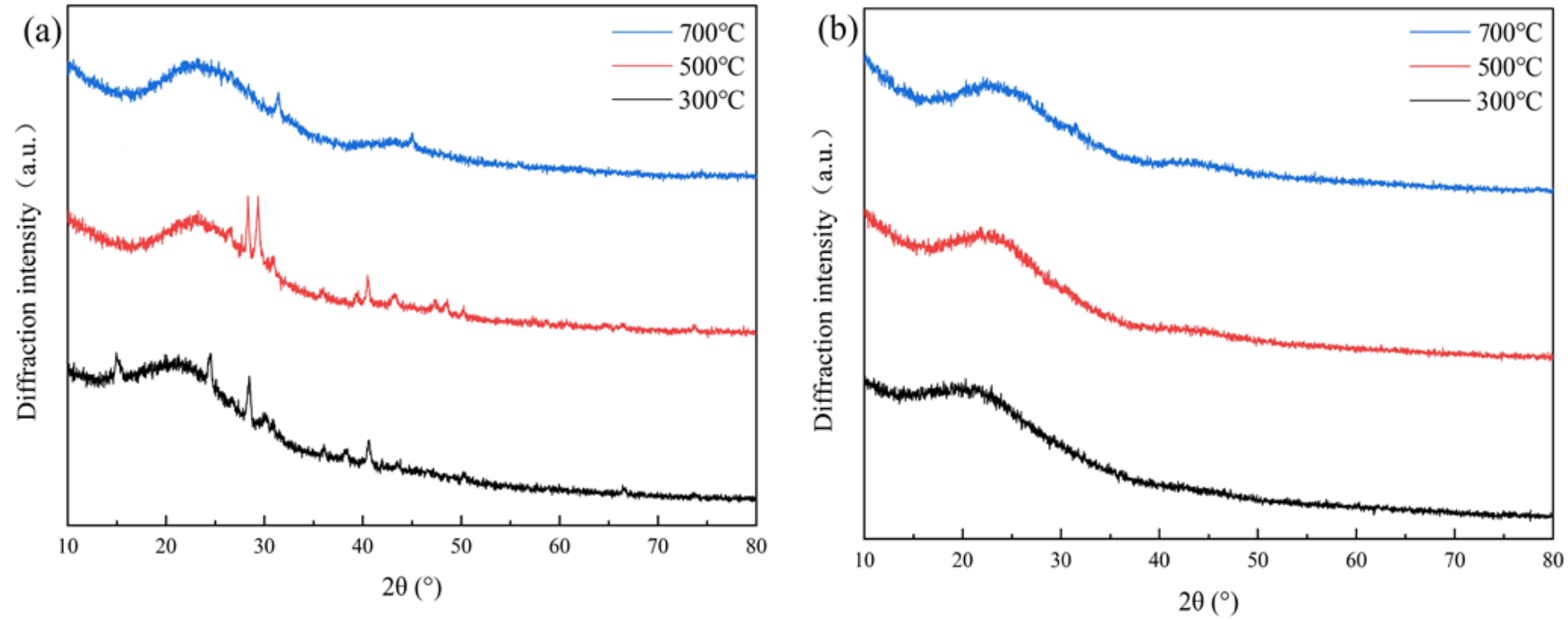

Figure 7

XRD pattern of biochar (a) rice straw biochar, (b) sugarcane bagasse biochar

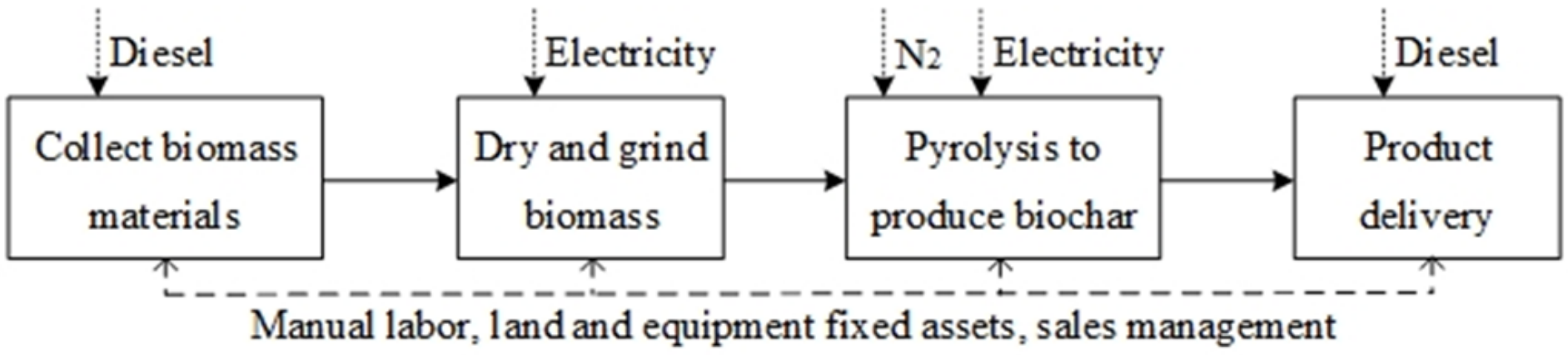

Figure 8 
Boundary diagram of biochar economic evaluation system

\section{Supplementary Files}

This is a list of supplementary files associated with this preprint. Click to download.

- GraphicAbstract.docx 